\title{
Comprehension and Application of the Ling 6 Sound Test
}

\author{
Hyejin Park', Jinsook Kim² \\ ${ }^{1}$ Department of Speech Pathology and Audiology, Graduate School, Hallym University, Chuncheon, Korea \\ ${ }^{2}$ Division of Speech Pathology and Audiology, College of Natural Sciences, Research Institute of Audiology and Speech Pathology, \\ Hallym University, Chuncheon, Korea
}

\section{Ling 6 Sound 검사의 이해와 적용}

\author{
박 혜 진 $\cdot$ 김 진 숙 ${ }^{2}$
}

한림대학교 일반대학원 언어병리청각학과 ${ }^{1}$ 한림대학교 자연과학대학 언어청각학부, 청각언어연구소 ${ }^{2}$

\begin{abstract}
Purpose: The purpose of this paper was to review the theoretical background and various approaches to use of the Ling 6 sound test, and to suggest an appropriate application method in Korea. Methods: The definition and history of the Ling 6 sound test and phonetic information about the six sounds used in the test, in English and Korean, were reviewed separately with related research. The information for the administration and variation of the original Ling 6 sound test, and application of those sounds in aural rehabilitation programs for infants and toddlers were provided. Results: The Ling 6 sounds have been widely used as a fast and easy assessment tool to examine the speech perception ability and provide validate information regarding the accessibility to speech frequencies, especially in very young children. Thus it has been recommended for parents conduct every day in order to check the function of the device or hearing status of their children. Conclusion: The Ling 6 sound test is useful and can be used regardless of type of hearing device and degree of hearing loss. The information in this paper will be able to provide comprehensive information about the Ling 6 sound test to the experts working with hearing impaired children.
\end{abstract}

Key Words: Ling 6, Speech perception, Hearing impaired children, Korean Aural Rehabilitation for Infants.

Received: July 19, 2016 / Revised: August 16, 2016 / Accepted: September 3, 2016

Correspondence: Jinsook Kim, Division of Speech Pathology and Audiology, College of Natural Sciences, Research Institute of Audiology and Speech Pathology, Hallym University, Hallymdaehak-gil 1, Chuncheon 24252, Korea

Tel: +82-33-248-2213 / Fax: +82-33-256-3420 / E-mail: jskim@hallym.ac.kr

\section{LING 6 SOUND 검사 사용의 적합성}

청각장애 아동이 청력 손실의 정도에 따라 청각보조장치를 착용한 후 말소리를 어느 정도 들을 수 있는지 확인하는 것은 청각재활에서 아동의 청력상태를 실시간으로 확인하고 아동의 보장구 선택 및 조절, 의사소통 방법과 언어발달의 목표 설정 등에 중요한 정보를 제공한다. 이에 여러 가지 방법으로 아동의 말소리 지각을 검사하는 방법이 개발되었는데, 대부분 방음실 에서 기기를 이용하여 어휘 목록을 제시하는 방식으로 검사를 시행한다. 그러나 구조화된 검사에서 요구하는 방식에 반응할 수 없는 어린 아동이나, 언어 발달 지체로 어휘력이 부족한 아 동의 경우에는 이런 방식의 공식적인 말지각 검사의 시행이 불 가능하다. 이러한 경우 Ling 6 sound 검사로 간단히 말소리 주
파수의 지각 정도를 확인할 수 있다.

Ling 6 sound 검사는 6 개의 말소리를 사용하여 말소리 지각 에 필요한 주파수 접근성을 파악하는 검사로, 개발자인 Daniel Ling의 이름을 기려 Ling 6 sound 검사라 한다(Ling, 1976, 2002). Ling 6 sound 검사는 원래 미국 영어 사용자를 대상으 로 개발되었으나 말소리 지각과 확인 능력을 빠르고 정확하게 확인할 수 있어 그 쓰임이 전 세계로 확산되었으며 현재 청각재 활 분야에서 보편적으로 사용되고 있다. 우리나라에서도 청각 재활 전문가들 사이에 널리 쓰이고 있으나, 검사에 대해 정확히 설명하는 문헌이 없어 전문가 개개인이 외국 자료를 참고하여 사용하고 있는 실정이다. 비록 외국의 사례이나 영어권인 호주 의 청능사 17 명을 대상으로 한 연구 결과, 전문가들이 Ling 6 sound 검사를 실시하는 방법이 일관되지 않고 Ling이 명시한 
검사 방법을 준수하는 청능사가 $17 \%$ 에 지나지 않아 보다 명확 하고 일관된 검사 실시 방법의 안내가 필요함을 지적한 것은 우 리에게도 시사하는 바가 크다(Agung et al., 2005). 따라서 본 고는 먼저 우리나라 말소리의 음향음성학적 특성을 보고한 선 행 연구 결과를 토대로 우리말 사용자를 대상으로 한 Ling 6 sound 검사 사용의 적합성을 살펴보고, 여러 문헌에 제시된 Ling 6 sound의 활용 방안을 정리하여 소개하고자 한다.

\section{Ling 6 sound는 무엇인가?}

Ling 6 sound 검사는 6 개의 말소리, 3 개의 모음 $(/ \mathrm{a} /, / \mathrm{i} /, / \mathrm{u} /)$ 과 3 개의 자음 $(/ \mathrm{m} /, / \mathrm{s} /, / \mathrm{s} /)$ 으로 시행하는 검사이다. Ling은 1970 년 $/ \mathrm{m} /$ 소리를 제외한 5 개의 소리로 5 sound 검사를 제안 하였으나, 이후 $/ \mathrm{m} /$ 소리를 목록에 추가하여 현재 널리 알려진 Ling 6 sound 검사가 되었다. 일반적으로 Ling 6 sound 검사라 고 명명하나, 묵음을 포함하여 Ling 7 sound 검사라고 하기도 한다(Blaiser, 2012). 묵음은 위의 6개 소리 외에 음성 산출 없 이 소리를 내는 흥내만 제시한 후 아동의 반응을 관찰하는 것 으로 아동이 소리의 유무를 정확히 인지하고 그 부재를 지각 하는지 파악하기 위한 것이다.

Ling 6 sound 검사의 6개 소리는 그 주파수가 250 8,000 Hz 사이에 고루 걸쳐 있어 말소리의 지각과 변별에 필수적인 주파 수 영역을 모두 포함한다(Ling, 1988). Figure 1은 영어를 사용 하는 남성 성인 화자와 청자가 약 $2 \mathrm{~m}$ 떨어진 거리에서 대화할 때 청자가 지각할 수 있는 6개 말소리의 주파수와 강도를 보여 준다(Ling, 1988). Figure 1에서 모음이 서로 다른 주파수 범위 에 두 번 걸쳐 제시된 것은 남성 성인 화자가 산출한 각 모음의 제1포먼트(F1)와 제2포먼트(F2)를 표시한 것이다. F1과 F2는 성도를 통과한 소리가 구강과 비강을 통과하면서 생기는 첫 번 째와 두 번째 공명주파수를 가리키는데, 이들은 말소리의 음색 결정에 관계된 것으로 알려져 있다(Lee \& Bae, 1987). F1과 F2 는 구개의 개방 정도와 혀의 움직임에 따라 그 값이 달라져 청 자에게 조음기관의 위치와 움직임 대한 정보를 제공한다. 따라 서 모음을 변별하고 자모음의 전이구간에 포함된 말소리 정보 를 확인하기 위해서는 F1과 F2가 산출되는 주파수를 모두 지 각할 수 있어야 한다(Sin, 2000). 또한 Ling 6 sound의 자음은 특정 주파수 영역에서 고유의 산출 에너지를 가지고 있어 이 주파수 영역의 소리를 감지해야 해당 소리를 정확히 확인할 수 있다. Ling 6 sound 검사는 이러한 원리를 바탕으로 말소리가 산출되는 가장 낮은 저주파수와 중주파수, 그리고 고주파수를 대역을 대표하는 말소리로 구성되어 말소리 지각에 필요한 전 주파수 영역을 포괄하게 된다.

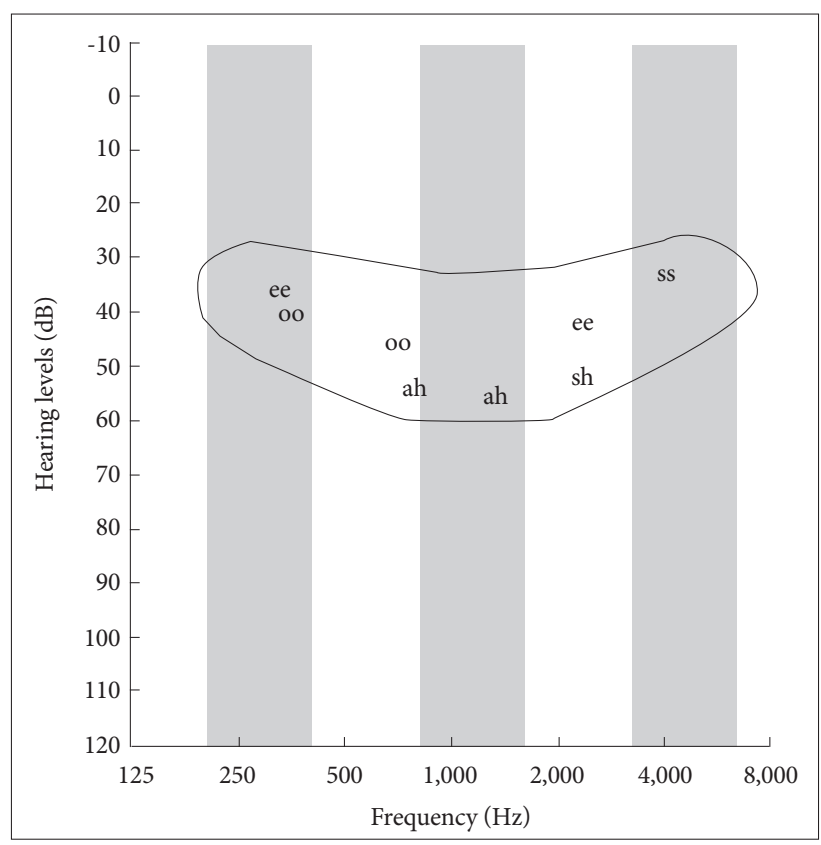

Figure 1. Ling 6 sounds on the audiogram. Adapted from Ling. The AlexanderGraham Bell Association for the Deaf 2010, with permission of The AlexanderGraham Bell Association for the Deaf.

\section{Ling 6 sound의 영어 말소리 정보}

Figure 1에서 영어를 사용하는 남성 성인 화자가 발화한 각 모음의 F1과 F2를 살펴보면, /a/는 약 $710 \mathrm{~Hz}$ 와 $1,100 \mathrm{~Hz}$, /i/는 $260 \mathrm{~Hz}$ 와 2,250 Hz, 그리고 /u/는 $270 \mathrm{~Hz}$ 와 $700 \mathrm{~Hz}$ 로, 3개 모 음의 F1은 약 $260 ~ 710 \mathrm{~Hz}, \mathrm{~F} 2$ 는 약 $700 ~ 2,250 \mathrm{~Hz}$ 사이의 저 주파수와 중주파수 영역에서 형성되는 것을 알 수 있다. 비음 은 조음 특성상 성대의 진동음이 구강과 비강 내에서 강화되고 흡수됨으로써 나타나는 공명 주파수를 보인다는 점에서 모음 과 비슷하지만, 모음과는 달리 특정 주파수 대역의 에너지가 감 소하는 반공명 주파수(antiresonance frequency)를 보여준다 (Johnson, 2011; Ohala \& Ohala, 1993; Pickett, 1980). 비음 / m/의 공명 주파수는 250 350 Hz에서(Ling, 1988), 반공명 주 파수는 1,000 1,500 Hz에서 형성되는데 반공명 주파수의 음향 신호가 약하기 때문에 $250 \mathrm{~Hz}$ 부근의 가장 낮은 주파수 영역에 서 가장 많은 소리 정보를 전달하게 된다(Ladefoged, 1993). 이 렇듯 $1,000 \mathrm{~Hz}$ 이하의 저주파수 영역은 분절적 소리 중 모음의 $\mathrm{F} 1$ 과 비음 $/ \mathrm{m} /$ 의 공명주파수를 포함하는 소리 정보를 전달하 며, 그 외에 남녀의 성별, 소리의 강도와 음도 등 소리의 초분절 적인 특성에 대한 기본 정보를 제공한다(Ling, 1988).

Ling 6 sound의 자음 $/ \mathrm{s} /$ 와 / $/ \mathrm{s}$ 는 고주파수 영역에서 가장 큰 에너지를 가지는 대표적인 소리이다. Figure 1은 자음 / / / 의 마 찰소리가 약 2,000 8,000 Hz에서 $50 \mathrm{~dB}$, /s/는 4,000 8,000 $\mathrm{Hz}$ 사이의 고주파수 영역에서 $30 \mathrm{~dB}$ 이상의 강도로 산출되어 야 청자가 듣고 확인할 수 있음을 가리킨다. 이 두 소리를 변별 
하려면 4,000 Hz 이상에서 $30 \mathrm{~dB}$ 정도의 강도로 산출되는 말 소리를 지각할 수 있어야 하는데, 비음 및 모음과 더불어 이 자 음들을 지각하고 확인할 수 있다면 $250 \mathrm{~Hz}$ 부터 $8,000 \mathrm{~Hz}$ 사이 의 소리 정보에 접근 가능함을 나타낸다. 따라서 일반적인 청력 도의 주파수 범위를 포함하게 되어 의미가 있다. 더 나아가 이는 Ling 6 sound에 포함되지 않았으나 1,000 4,000 Hz 영역에서 조음 방법과 위치 정보가 전달되는 파열음 $(/ \mathrm{p} /, / \mathrm{t} /, / \mathrm{k} /)$ 이나 유 음 $(/ 1 /, / \mathrm{r} /)$ 등의 소리 정보를 지각할 수 있음을 의미한다(Ling, 2002).

그러므로 Ling 6 sound 검사에서 청각장애 아동이 각 말소 리를 듣고 확인할 수 있다면 모든 말소리 지각에 필요한 분절 적 정보와 초분절적 정보를 지각할 수 있는 주파수 분석능력이 있다고 유추할 수 있다. 만약 아동이 $3 \mathrm{~m}$ 거리에서 $/ \mathrm{m} /$ 소리에 반응하지 않는다면 이는 아동이 대화와 같은 연속된 말소리의 저주파수 정보를 적절히 듣지 못하고 있음을 가리키고, 이 경 우 저주파수에 포함되어 전달되는 음도나 억양 등의 정보 습득 에 어려움을 유발하여 비정상적인 음도를 사용하거나 아동의 말소리가 비음화될 수 있다(Ling, 2002). 또한 만약 가까운 거 리에서도 /s/나 / / / 소리에 반응이 없다면 같은 주파수 대역에 서 정보가 전달되는 유사한 자음을 정확히 듣지 못할 수 있다 는 것을 의미한다.

\section{Ling 6 sound의 우리말 말소리 정보}

음성학 및 언어병리학, 청각학 등의 분야에서 이루어진 우리 말 단모음 주파수에 대한 연구 결과를 살펴보면 Ling 6의 모음 과 대응되는 한국어 모음 $/ \mathrm{a} /, / \mathrm{i} /, \mathrm{l} / \mathrm{/}$ 의 F1과 F2는 대체로 영어 의 모음과 유사한 값을 가지는 것으로 나타난다. 20 70대 남성 922명을 대상으로 단모음의 연령 및 성별의 차이를 연구한 Kim et al.(2013)는 남성 화자가 단독으로 산출한 모음의 F1, F2 평 균은 /a/의 경우, 각각 $668 \mathrm{~Hz}, 1,108 \mathrm{~Hz}, / \mathrm{i} /$ 는 $303 \mathrm{~Hz}, 2,153$ $\mathrm{Hz}, / \mathrm{u} /$ 는 $408 \mathrm{~Hz}, 1,060 \mathrm{~Hz}$ 라고 보고하였고, 단모음이 아닌 연결발화에서 20대 성인 남성 10명이 산출한 모음의 주파수 특 성을 분석한 Lee et al.(2005)은 /a/의 F1과 F2는 $651 \mathrm{~Hz}, 1,156$ $\mathrm{Hz}, / \mathrm{i} /$ 는 $236 \mathrm{~Hz}, 2,183 \mathrm{~Hz}, / \mathrm{u} /$ 는 $324 \mathrm{~Hz}, 595 \mathrm{~Hz}$ 로 보고하 고 있다. 모음이 산출된 언어적 맥락과 대상자의 연령 및 지역 분포 등의 차이로 인해 두 연구에서 /a/를 제외한 /i/s와 /u/ 모 음의 F1과 F2의 값이 다소 다르게 나타났으나, 전반적으로 /i/ 와 /u/의 F1은 230 408 Hz, /u/의 F2는 595 1,060 Hz 사이의 저주파수 영역에서, $/ \mathrm{i} /$ 의 $\mathrm{F} 2$ 는 $2,000 \mathrm{~Hz}$ 이상의 고주파수 영역 에서 산출된다는 점에서 Ling 6에 사용된 영어 모음과 유사한 주파수 분포를 보인다.

모음에 비해 자음의 주파수 연구는 상대적으로 적은 편인데, 한국어의 비음 $/ \mathrm{m} /$ 은 영어에서와 마찬가지로 단어 내 위치에
관계 없이 240 $250 \mathrm{~Hz}$ 부근에서 가장 큰 에너지를 가진 공명 주파수가 산출되는 것으로 보고되고 있다(Kim et al., 2013; Lee et al., 2005; Sin, 2000). Ling 6 sound의 / / / 소리는 우리 말에서는 '시이 '위' 등의 이중모음과 결합할 때 나타나는 소리 와 가까운데, 이때 '소소리는 약 3,500 6,000 Hz 사이에서 가 장 많은 마찰 에너지를 산출한다(Kim et al., 2010). 비슷한 조 음 방법을 사용하는 자음들은 음향학적으로 비슷한 주파수 대 역에서 에너지를 산출하는데, 우리말에서 파열과 마찰을 동시 에 사용하는 /ㅊ/, / ㅉ/ 등의 파찰음은 3,500 5,500 Hz에 걸친 고주파수 대역에서 가장 큰 에너지가 산출되는 것으로 나타나 (Jeong, 2007; Lee et al., 2005), / / /를 확인할 수 있다면 같은 주파수 대역에서 큰 에너지가 산출되는 파찰음 또한 지각할 수 있으리라 유추할 수 있다. Ling 6 sound의/s/ 소리는 우리말에 서 단모음과 결합되어 발음되는 ' $ᄉ$ ' 소리로 살펴볼 수 있다. 우 리말 소리의/s/는 자음 중 가장 높은 4,000 8,000 Hz의 주파 수 범위에서 산출되며(Kim et al., 2010), 평음 /s/(ㅅ)는 약 6,200 $\mathrm{Hz}$ 에서, 경음 $/ \mathrm{s}^{*} /($ ㅆㄴ는 $6,600 \mathrm{~Hz}$ 에서 가장 강한 마찰 소음이 산출되는 것으로 나타났다(Cho et al., 2000; Lee et al., 2005).

위의 연구 결과를 종합하면, 우리말의 모음 /a/, / i// / / / 와 자 음 $/ \mathrm{m} /, / \mathrm{s} / \mathrm{s} / \mathrm{s} /$ 도 영어와 마찬가지로 대략 250 8,000 Hz 사이 의 소리를 들을 수 있어야 변별 및 확인이 가능하여 저주파수 에서 고주파수에 이르는 전 주파수 영역을 포괄하고 있음을 알 수 있다. 양순음과 치조음, 경구개음의 로커스 주파수(locus frequency)가 각각 $1,000 \mathrm{~Hz}, 2,000 \mathrm{~Hz}, 3,000 \mathrm{~Hz}$ 내외에 위치 하고(Sin, 2000), 우리말 모음 환경에 따라 양순파열음은 1,000 $2,500 \mathrm{~Hz}$, 치조파열음은 $3,800 ~ 4,800 \mathrm{~Hz}$, 연구개파열음은 $650 \sim 3,300 \mathrm{~Hz}$ 의 주파수 범위에서 파열 에너지가 나타난다는 점을 고려할 때(Lee et al., 2005), 우리말에서도 Ling 6 sound 를 모두 확인할 수 있으면 그 사이 주파수 영역에서 전달되는 소리 정보를 지각, 변별, 확인할 수 있을 것으로 기대할 수 있다. Figure 2는 우리말 소리를 사용했을 때 Ling 6 sound의 각 소 리가 위치하는 주파수 영역을 보여준다. 우리말 소리의 기본 구 조는 자음과 모음이 결합한 음절구조이지만, Ling 6 sound 검 사의 소리는 자음이나 모음을 단독으로 사용하는 것이기 때문 에, 음절구조로 표기된 글자로 인한 혼동을 막고자 Ling 6 sound 검사음의 음소를 한글이 아닌 국제음성기호로 표기하 였다. 일반적으로 모음 $/ \mathrm{a} /$ 가 가장 큰 에너지를 가지고 있고 자 음 $/ \mathrm{s} /$ 의 에너지가 가장 작지만, 소리의 강도는 화자와 거리에 따라 달라진다. 


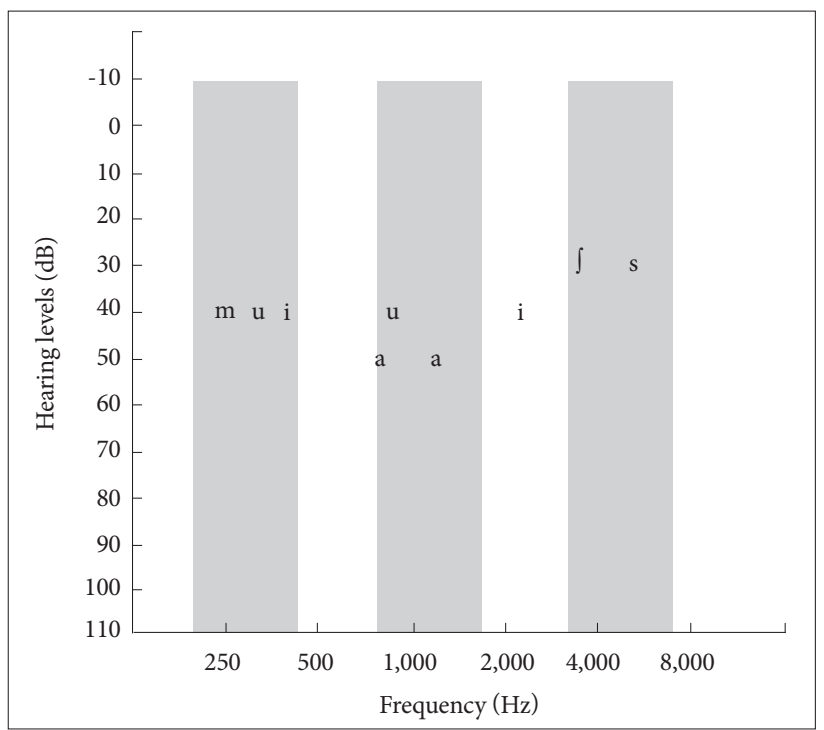

Figure 2. The frequency ranges of the Ling 6 sounds in Korean on the audiogram.

\section{LING 6 SOUND 검사의 활용방안}

\section{Ling 6 sound 검사의 목표 및 실시 방법}

Ling은 그의 저서 "Foundations of spoken language for hearing impaired children"에서 Ling 6 sound를 이용해 소리 의 감지(지각)와 확인 여부를 검사할 수 있다고 기술하고 있다 (Ling, 1988). 듣기 기술은 그 위계에 따라 소리의 감지(지각), 변별, 확인, 이해의 4 단계로 나누어 볼 수 있는데(Erber, 1982), 소리 감지는 소리의 유무를 인식하는 단계로 모든 듣기 기술의 출발점이 된다(Tye-Murray \& Clark, 1998). 소리 변별은 감지 한 소리의 같고 다름을 인지하는 단계이고, 소리 확인은 들은 소리가 무엇인지를 말하거나 가리킬 수 있는 단계를 가리킨다. 따라서 소리의 감지와 확인 여부를 검사할 수 있다는 것은 Ling 6 sound의 말소리를 감지할 수 있는지, 혹은 들은 말소리가 무 엇인지를 알 수 있는지를 파악할 수 있다는 뜻이다.

일반적으로 아동의 연령이 어리거나, 언어습득 이전에 청각 재활을 처음 시작하는 시기라면 소리 감지가 Ling 6 sound 검 사의 목표가 된다. 소리 감지에 대한 반응은 아동의 연령에 따 라 달라질 수 있는데, 6개월경의 어린 아동이라 하더라도 소리 를 들으면 하던 행동을 멈추거나, 소리가 들리는 쪽으로 고개를 돌리는 등의 반응을 보일 수 있다. 큰 아동들은 소리를 들었을 때 박수치기, 손 들기, 고리 끼우기, 장난감 통에 넣기, 퍼즐 맞 추기 등 다양한 방법을 사용하여 구조화된 방식으로 검사할 수 있다(Kim, 2014).

만약 아동이 말소리를 이해할 수 있거나 따라 말할 수 있으 면 소리 확인이 검사의 목표가 된다. 아동의 발달 여부에 따라 장난감이나 그림카드를 이용해 Ling 6 sound의 각 소리를 들
려주고 들은 소리에 해당하는 사물을 고르도록 하거나, 들은 소리를 따라 말하게 하는 방법으로 검사한다. 만약 아동이 글 자를 안다면 그림 대신 소리에 해당하는 글자를 고르게 할 수 도 있다.

Ling 6 sound 검사는 말소리를 이용하기 때문에 다른 장비 가 필요하지 않고 검사 방법이 비교적 용이하여, 전문가와 함께 검사 방법을 숙지한다면 청능사와 언어재활사뿐 아니라 교사 나 아동의 부모 등 누구나 빠르고 간단하게 실시할 수 있다. Ling 6 sound 검사의 기본적인 실시 방법을 정리하면 다음과 같다.

1) TV, 에어컨, 선풍기, 공기 정화기, 가습기 등 생활 속에서 소음을 만드는 장치는 모두 전원을 끄고 조용한 환경을 조성 한다.

2) Ling 6 sound와 함께 사용하는 장난감이나 카드를 준비 하여 아동 앞에 놓는다. 아동이 따라 말할 수 있고, 검사를 실 시하는 동안 잘 협조할 수 있다면 장난감은 준비하지 않아도 무방하다.

3) 검사자는 아동으로부터 약 0.3 1 m 되는 거리에, 아동의 옆이나 뒤에 위치한다. 아동의 앞에 위치할 때는 아동이 검사 자의 입을 보지 못하도록 손, 종이, 가림막 등으로 입을 가린다. 이때 입을 가리는 물체로 인해 소리의 성질이 왜곡되지 않도록 입으로부터 충분한 거리를 유지해야 한다.

4) 검사자는 Ling 6 sound 중 하나의 소리를 산출한다. /s/, / / / 소리에서는 조음 시 산출되는 마찰 소음이 검사의 목표음이 므로, 소리를 산출할 때 /스/나/쉬/처럼 모음을 결합하지 말고 $/ \mathrm{s} /$ 와 $/ \mathrm{J} /$ 의 마찰 소음만 산출해야 한다. 또한 소리는 평소 대화 할 때와 같은 크기로 제시하고, 너무 크거나 작은 소리를 내지 않도록 주의한다.

5) 소리에 대한 아동의 반응을 기록한다.

6) 아동이 소리를 감지하거나 확인하는 등 적절하게 반응했 다면 미소나 환호, 칭찬 등 아동에게 알맞은 방법으로 충분히 보상해 준다.

7) 아동이 예측하지 못하도록 Ling 6 sound의 순서를 무작 위로 제시하고, 소리와 소리 사이의 간격은 일관되지 않도록 한 다. 간혹 묵음을 제시하여 소리의 유무에 대한 아동의 지각을 확인한다.

Ling 6 sound 검사를 실시할 때 검사자가 되도록 아동의 시 야 밖에 위치하는 것은 입모양뿐 아니라 몸의 움직임도 검사자 가 소리를 산출함을 알리는 단서가 될 수 있기 때문이다. 아동 이 아직 검사에 익숙하지 않을 때는 검사자 외에 다른 가족이나 전문가가 아동과 함께 활동하며 소리 반응을 유도하거나 시범 을 보여서 검사 시행 전 아동이 과제를 이해하도록 돕는다. 이렇 게 소리에 반응하는 연습은 아동이 청력검사실에서 검사음에 
반응하는 것을 연습할 수 있는 기회가 되기도 한다(YoshinagaItano, 2000). 또한 Ling 6 sound와 함께 묵음에 반응하는 연 습을 할 수 있는데, 이는 아동이 소리가 안 들렸음을 표현하는 것을 배울 수 있는 기회가 된다. 아동이 검사에 익숙하지 않아 연습이 필요한 시기에는 양이의 청각보조장치를 모두 착용한 상태에서 연습 및 검사를 진행하며, 아동이 검사에 익숙해지고 잘 반응하면 양쪽 귀를 번갈아 한 쪽 보장구를 빼고 검사하여 각 귀의 수행 정도를 확인한다.

Ling 6 sound 검사에서 각 소리와 연결하여 장난감이나 카 드로 제시하는 사물은 그 이름이나 활동을 나타내는 소리가 Ling 6 sound 중 하나로 시작되는 것을 사용한다. Figure 3은 영어에서 Ling 6 sound와 함께 주로 사용되는 어휘의 대표적 인 예를 보여준다. 선택한 어휘에 약간의 차이는 있으나, 해당 소리로 시작하는 명사나 의성어, 의태어를 사용하고 있음을 알 수 있다.
Figure 3의 어휘들은 영어권의 Ling 6 sound 연습 및 검사 에 보편적으로 쓰이고 있는데, $/ \mathrm{m} /, / \mathrm{s} /, / \mathrm{s} /$ 소리에 해당하는 소 리는 언어와 문화에 관계없이 우리말 소리에도 적용 가능하지 만, /a/, /i/, /u/에 해당하는 소리는 영어의 어휘와 의성어 등을 대표하고 있어 우리 말과 문화에 맞는 어휘로 대체하여 사용해 야 한다. Figure 3의 예에서 알 수 있듯이 아동의 어휘 수준에 적합하고 해당 소리와 어울리면 무엇이든 Ling 6 sound와 연결 된 어휘로 사용할 수 있는데, 어린 아동들의 경우 아동의 어휘 및 인지 수준에 맞는 소리를 사용하는 것이 소리에 대한 아동 의 흥미를 유발하고 유지하는 데 도움이 된다. Figure 4는 영유 아 아동들을 대상으로 Ling 6 sound의 각 소리와 짝을 이룰 수 있는 사물과 활동의 예로, 현재 개발중인 '한국 영유아 청각 재활(Korean Aural Rehabilitation for Infants, KARI)' 프로 그램에서 사용하고 있는 것들이다. KARI는 어린 아동들의 자 연스러운 듣기 및 말하기 환경을 청각재활에 활용하는 것에 초

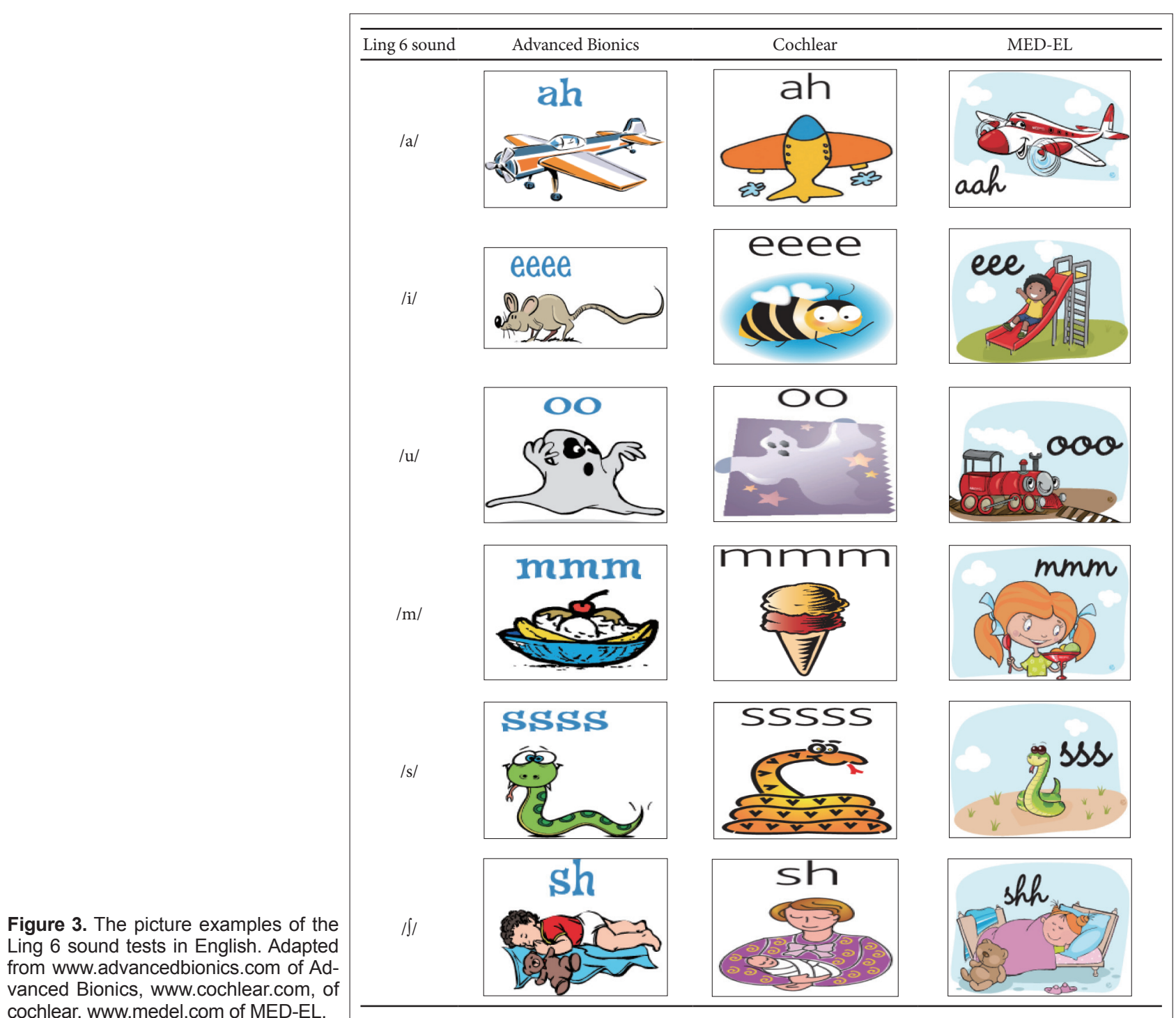


점을 맞추고 있는데, 예를 들어 $/ \mathrm{a} /$ 소리에 아이스크림이나 음 식을 먹는 흥내를 내며 /아-/라고 말하거나, /a/ 소리와 아이스 크림'이라는 단어를 연결하여 놀이활동을 한다. 또 /a/ 모음으로 시작하는 '빵빵'이나 ‘아빠를 /a/ 소리와 함께 사용할 수도 있다. /i/ 소리는 '위이잉'(비행기), '치카치카'(칫솔), '입'(입술), '끼끼'(원 숭이), '찍찍'(쥐), / $\mathrm{u} /$ 소리는 ‘우유', '눈' 또는 '주세요', $/ \mathrm{m} /$ 소리 에는 ‘음메'(송아지)나 ‘멍멍'(강아지), /s/ 소리에는 ‘밤'이나 '스케 이트,' / / / 소리에는 '쉿’ 또는 ‘쉬’ 소리를 이용하여 각 소리를 연 결하여 기억할 수 있도록 촉진한다. Figure 4에 제시한 어휘들 이 우리말 Ling 6 sound와 연결하여 많이 쓰이지만, 그 외에도 아동이 특히 흥미를 보이거나 좋아하는 사물이나 활동이 있다 면 그 소리를 구성하는 자음이나 모음, 상황 등을 고려하여 아 동 고유의 Ling 6 sound 어휘로 사용할 수 있다. 아동과 Ling 6 sound의 소리를 감지하는 연습을 하면서 이러한 장난감이나 그림카드를 활용할 수 있는데, 초기에는 아동이 소리를 잘 기 억할 수 있도록 각 소리마다 한 가지 어휘를 정해서 연습하는
것이 좋다.

\section{Ling 6 sound 검사의 활용}

Ling 6 sound 검사는 단시간 안에 빠르고 정확하게 아동이 말소리를 지각하거나 확인하는 정도를 검사할 수 있고, 그 결 과에 대한 신뢰도가 높아 모든 종류의 청각보조장치 적합 후 말소리 지각 능력을 알기 위한 기본 검사로서 검사도구 구성에 포함되어 있다(Scollie et al., 2012; Sennaroglu et al., 2009). 현 재 우리나라에서 출판된 말지각 관련 검사 중 Ling 6 sound 검 사를 포함하고 있는 것은 '청각언어재활을 위한 평가가이드 검 사(Evaluation of Auditory Response to Speech-Korean, EARS-K) (Lee et al., 2003)'와 '국립특수교육원 말지각 발달 검사(KNISE-DASP) (Song et al., 2010)'이다. EARS-K에서는 글자 및 그림을 이용하여 간단히 각 말소리의 지각 및 확인능 력을 검사하도록 구성하고 있으며, KNISE-DASP는 Ling 6 sound 검사에서 소리의 감지 및 글자와 그림을 이용한 확인,

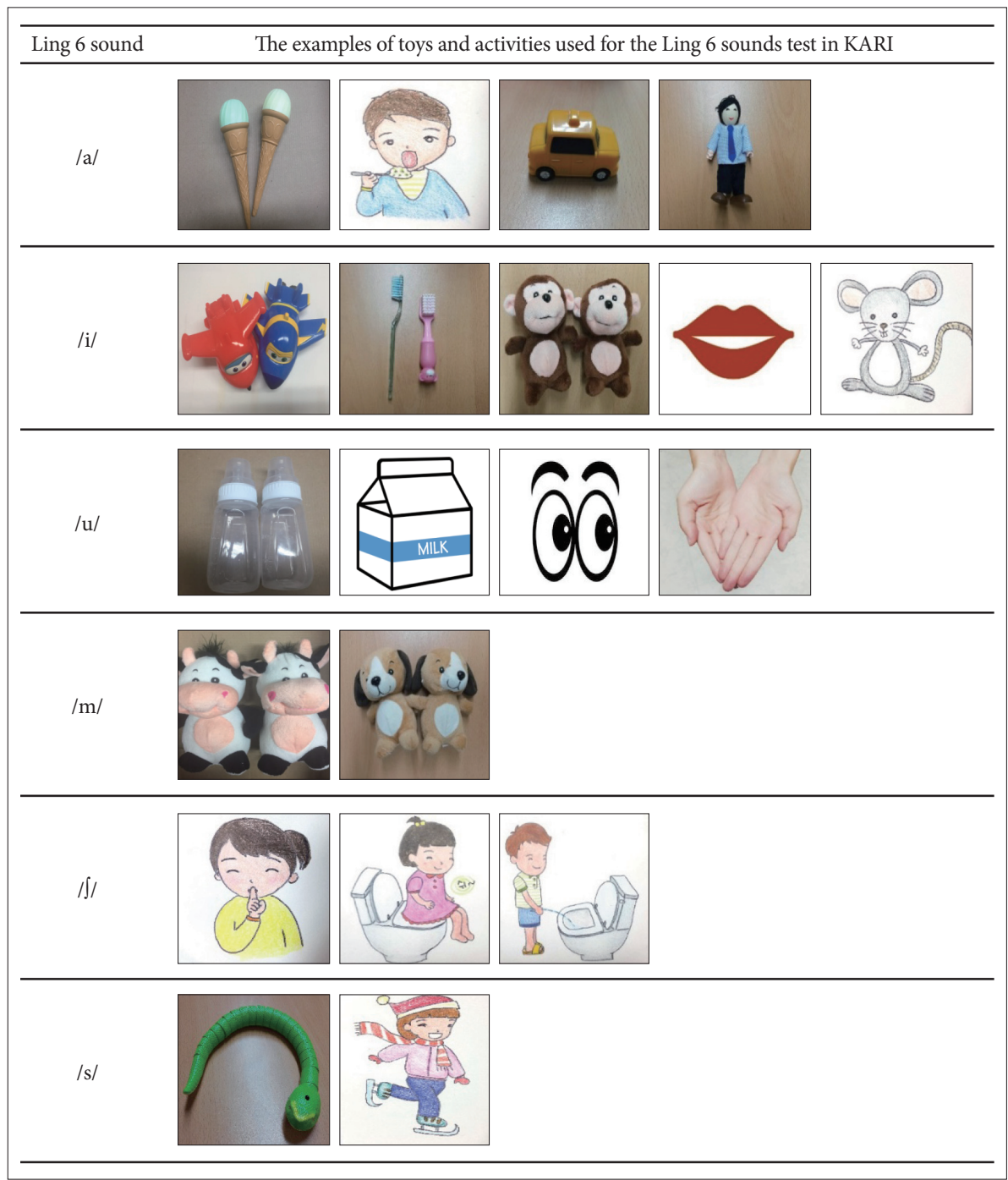

Figure 4. The examples of toys and activities which are used for the Ling 6 sounds test in KARI. KARI: Korean Aural Rehabilitation for Infants. 
그리고 필요에 따라 소리 변별 능력을 검사하고 아동의 반응 을 기록할 수 있도록 기록지를 제시하고 있다. Figure 5와 6은 $\mathrm{KNISE}-\mathrm{DASP}$ 의 Ling 6 sound 검사에서 사용하는 기록지와 그림의 예시이다.

Figure 5에서 볼 수 있듯이 KNISE-DASP의 Ling 6 sound 감지 검사는 $1 \mathrm{~m}$ 에서 아동의 소리 감지 반응을 확인한 후 $2 \mathrm{~m}$, $3 \mathrm{~m}$ 이상으로 거리를 늘려 다양한 거리에서 아동의 반응을 기 록하도록 하고 있는데, 이는 두 사람이 일대일로 대화할 때 청

\begin{tabular}{|c|c|c|c|c|c|c|c|c|c|c|}
\hline Detect. & $1 \mathrm{~m}$ & $2 \mathrm{~m}$ & $-\mathrm{m}$ & Ident. & $\mathrm{m}$ & $\mathrm{a}$ & $\mathrm{i}$ & $\int$ & $\mathrm{s}$ & N.R. \\
\hline $\mathrm{m}$ & & & & $\mathrm{m}$ & & & & & & \\
\hline $\mathrm{u}$ & & & & $\mathrm{u}$ & & & & & & \\
\hline $\mathrm{a}$ & & & & $\mathrm{a}$ & & & & & & \\
\hline $\mathrm{i}$ & & & & $\mathrm{i}$ & & & & & & \\
\hline $\int$ & & & & $\int$ & & & & & & \\
\hline$s$ & & & & $\mathrm{~s}$ & & & & & & \\
\hline Score & $/ 12$ & $/ 12$ & $/ 12$ & Score & 13 & 13 & 13 & 13 & 13 & \\
\hline \multicolumn{4}{|c|}{ Detection test } & \multicolumn{7}{|c|}{ Identification test } \\
\hline \multirow{2}{*}{ S II } & \multicolumn{6}{|c|}{ S I } & & & & \\
\hline & $\mathrm{m}$ & $\mathrm{u}$ & & $\mathrm{i}$ & $\int$ & $\mathrm{s}$ & & & & \\
\hline $\mathrm{m}$ & & & & & & & & & & \\
\hline $\mathrm{u}$ & & & & & & & & & & \\
\hline a & & & & & & & & & & \\
\hline $\mathrm{i}$ & & & & & & & & & & \\
\hline $\int$ & & & & & & & & & & \\
\hline $\mathrm{s}$ & & & & & & & & & & \\
\hline Score & $/ 12$ & $/ 12$ & /1 1 & $/ 12$ & $/ 12$ & $/ 12$ & & & & \\
\hline
\end{tabular}

Figure 5. Examples of the Ling 6 sound test recording sheet. The original recording sheet is written in Korean. Please see the KNISEDASP manual for the detailed instruction. N.R.: No Response, S I: Stimulation I, S II: Stimulation II. Adapted from Song et al. Korea National Insitute for Special Education 2010, with Permission Korea National Insitute for Special Education.

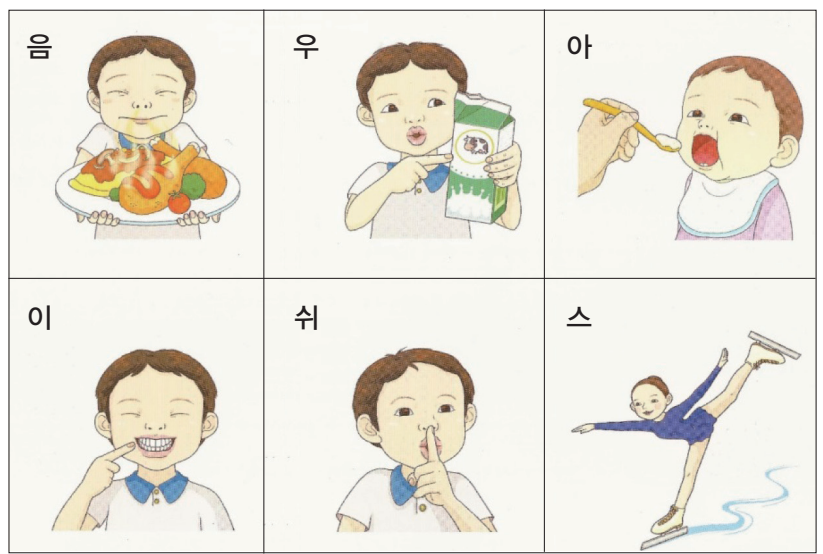

Figure 6. The picture for the Ling 6 sound identification test in KNISE-DASP. Adapted from Song et al. Korea National Insitute for Special Education 2010, with Permission Korea National Insitute for Special Education.
자와 화자 간의 평균 거리가 $2 \mathrm{~m}$ 이고, 3 인 이상이 집단으로 대 화할 때 평균 $3 \mathrm{~m}$ 이상의 거리에서 소리가 산출됨을 고려하여 다양한 거리에서 아동의 반응을 관찰하도록 한 Ling의 제안을 따른 것이다(Ling, 2002). 아동이 말소리를 감지하거나 확인하 는 거리를 체크하는 것은 듣기 기술의 변화를 확인하고, 청각 보조장치 조절과 언어 습득을 촉진하는 환경 조성에 필요한 정 보를 제공받을 수 있다는 점에서 중요하다.

이렇듯 소리를 들을 수 있는 거리 확인의 중요성 때문에 전 문가들은 청각보조장치의 특성을 고려하여 보청기를 착용한 아동들이 $0.2 \sim 0.3 \mathrm{~m}$ 이내의 거리에서, 인공와우를 사용하는 아 동은 약 $1 \mathrm{~m}$ 거리에서 Ling 6 sound를 모두 듣는지 확인한 후 점차 $1,2,3 \mathrm{~m}$ 이상 등으로 거리를 넓혀가며 아동의 반응을 확 인하도록 제안하기도 한다(Cole \& Flexer, 2015). 이를 반영하 여 외국의 재활 프로그램에서는 먼저 약 $0.2 \mathrm{~m}$ 거리에서 Ling 6 sound를 이용한 소리 감지 반응을 확인한 후 점차 거리를 늘 려 원거리 검사를 시행하고, 검사한 거리를 명시하도록 하고 있 다(www.cochlear.com). 또한 대화가 이루어지는 상황은 대부 분 생활 소음이 있는 환경이기 때문에 소음이 있는 상황에서 말 소리를 지각할 수 있는지를 파악하는 것이 청각장애를 가진 아 동과 성인의 일상 생활에서의 의사소통 능력을 파악하는 데 중요 하다. 이에 Early Listening Function (ELF) (Anderson, 2000) 을 개발한 Anderson은 ELF의 개념을 응용하여 거리와 소음 유무에 따른 Ling 6 sound의 수행을 검사하고 기록할 수 있도 록 ELFLing (Anderson, 2016)을 제안하기도 하였다. Figure 7 은 소음과 거리를 표시하는 ELFLing의 기록지 예이다.

보청기나 인공와우 적합 후 Ling 6 sound 검사를 실시했을 때의 장점 중 하나는 청각보조장치 사용자가 실제 감지하고 확 인할 수 있는 말소리 정보를 체크할 수 있다는 것인데, 이는 청 력검사를 굳이 하지 않아도 재활시간에 간단히 검사할 수 있어 청각보조장치의 기능을 빠르게 확인할 수 있을 뿐 아니라, 순 음청력검사 결과만으로는 확인할 수 없는 정보를 얻을 수 있는 방법이기도 하다. 더욱이 $\operatorname{Ling}(1988)$ 은 보청기 조절 프로토콜 의 마지막 단계에서 Ling 6 sound 검사를 이용하여 적합 타당 성을 검증하도록 권고하였는데, Ling의 권고는 인공와우를 사 용하는 아동들에게도 적용할 수 있다. 이는 보청기나 인공와우 적합 후 $1 \mathrm{~m}$ 의 거리에서 Ling 6 sound 검사를 실시하여 각 소 리의 반응을 확인한 후, 아동이 지각이나 확인에 어려움을 보이 는 소리의 해당 주파수와 강도를 조절하여 아동이 말소리 지각 에 필요한 주파수를 모두 들을 수 있도록 확인하는 절차를 거 치는 것을 뜻한다. 특히 아직 언어습득 이전 단계인 유소아의 경 우 보청기나 인공와우 적합 후 말소리 주파수에의 접근성을 빠 르게 확인할 수 있어 적합 타당성을 확인할 수 있을 뿐 아니라, 기계적으로 계산된 보장구 이득의 실제 효과를 파악하는 데에 


\begin{tabular}{|c|c|c|c|c|c|}
\hline \multirow{2}{*}{$\begin{array}{l}\text { Quiet } \square \\
\text { Ling sound }\end{array}$} & \multicolumn{2}{|c|}{ Noise $\square$ Source } & \multicolumn{2}{|c|}{ Amplification } & \multirow{2}{*}{$\overline{1 \text { Foot }}$} \\
\hline & 15 Feet next room & 10 Feet & 6 Feet & 3 Feet & \\
\hline \multicolumn{6}{|l|}{$\mathrm{OO}$} \\
\hline \multicolumn{6}{|l|}{ AA } \\
\hline \multicolumn{6}{|l|}{ EE } \\
\hline \multicolumn{6}{|l|}{ M } \\
\hline \multicolumn{6}{|l|}{ SH } \\
\hline \multicolumn{6}{|l|}{ S } \\
\hline VOICELESS TH & & & & & \\
\hline
\end{tabular}

Figure 7. The early listening function test using Ling sounds (ELFLing). Adapted from http://successforkidswithhearingloss.com/tests, of supporting success of children with hearing loss.

도 매우 유용하다(Smiley et al., 2004; Winter \& Kuk, 1998). 최 근의 연구 결과에서 보청기를 사용한 상태에서 Ling 6 sound 를 이용한 청력검사 결과가 보청기의 조절 상태에 따른 주파수 차이에 매우 민감하여 넓은 범위의 주파수 접근성을 검사할 수 있음을 증명한 것은 Ling 6 sound의 임상적 의의를 잘 보여준 다(Glista et al., 2009; Wolfe et al., 2010, 2011). 이에 최근에는 보청기 착용 효과의 평가를 위해 Ling 6 sound를 $\mathrm{dB} \mathrm{HL}$ 로 조 율하여 객관적 검사에 활용하는 연구가 진행되고 있다(Scollie et al., 2012).

Ling 6 sound 검사의 또 다른 장점은 청각장애 유소아 아동 의 부모가 검사 방법을 숙지한 후 집에서 간단하게 시행하여 아동의 청각 상태를 확인할 수 있다는 점이다. 어린 아동들은 청력에 변화가 있거나 사용하고 있는 청각보조장치에 이상이 있는 경우에 이를 인지하거나 표현하지 못하는 경우가 대부분 이다. 그러나 Ling 6 sound 검사는 전 주파수에 걸쳐 아동의 말소리 지각 및 확인에 대한 정보를 제공하기 때문에 매일 청각 보조장치를 착용한 후 Ling 6 sound 검사를 시행하면 보호자 가 변화를 즉각 인지하고 알맞은 조치를 할 수 있다. 일측성 난 청이나 경도 난청이 있는 경우에도 주기적으로 이 검사를 시행 하면 부모가 아동의 청력 변화 정도를 빨리 확인할 수 있다. 이 에 전문가들은 Ling 6 sound 검사를 매일 청각보조장치 착용 후 체크해야 하는 기본 검사 중의 하나로 제안하고, 부모가 지 속적으로 아동의 청각상태를 점검할 것을 권고한다(Desjardin, 2003; Smiley, 2004). 특히 듣기를 통한 구어발달을 촉진하고 자 하는 경우에는 아동의 청각상태를 최적으로 유지하는 것이 중요하기 때문에 청각구어 접근법(auditory verbal approach) 에서는 영유아의 청각재활을 담당하는 전문가가 아동의 부모 에게 검사의 중요성 및 방법을 알려주어 집에서 정기적으로 청 각상태를 확인하고, 매 회기를 시작할 때 아동의 듣기 상태를 점검하도록 권고하고 있다.

\section{CONCULSIONS}

이상에서 살펴본 바와 같이 Ling 6 sound 검사는 우리말 소 리의 전달에 필요한 주파수 영역을 모두 포함하고 있으며, 청각 장애인의 연령이나 청각보조장치의 종류에 관계 없이 6 개의 말 소리로 전 주파수 영역의 말소리 접근성을 파악할 수 있는 검 사이다. 또한 특별한 장비가 필요하지 않고 전문가뿐 아니라 아 동의 부모도 쉽게 검사 방법을 익힐 수 있어 아직 공식적인 검 사가 불가능하거나 언어발달이 이루어지지 않은 아동의 청각 보조장치 적합 효과 및 청각상태 변화 점검에 매우 유용하다. 이에 초기에 Ling이 제안한 검사가 거리와 소음까지 고려하여 검사하는 방법으로 발달하였고, 현재 전 세계적으로 말지각 검 사 및 청각재활의 출발점으로 널리 사용되고 있다. 우리나라에 서도 청각재활 전문가들이 그 시행 방법을 정확히 숙지하고 청 각장애 아동의 가족들이 이를 주기적으로 실시할 수 있도록 돕는다면 특히 공식검사가 어려운 영유아의 청각재활에 큰 도 움이 될 것으로 기대한다.

중심 단어 : Ling 6 -말지각-청각장애 아동 - 한국 영유아 청각 재활.

\section{REFERENCES}

Advanced Bionics. (2009). The ling six sounds. Retrieved from https://www. advancedbionics.com/content/dam/ab/Global/en_ce/documents/libraries/AssessmentTools/3-01066-B-2_Ling\%20Six\%20Sounds-FNL. pdf.

Agung, K. B., Purdy, S. C., \& Kitamura, C. (2005). The Ling Sound Test Revisited. Australian and New Zealand Journal of Audiology, 27(1), 33-41.

Anderson, K. (2000). Early Listening Function (ELF). In J. R. Madell \& C. A. Flexer (Eds.). Pediatric Audiology: Diagnosis, Technology, and Management (pp.45-53). New York, NY: Thieme Medical Publishers.

Anderson, K. (2016, October 17). The early listening function using the ling sounds. Supporting success for children with hearing loss. Retrieved from http://successforkidswithhearingloss.com/tests.

Blaiser, K. (2012). Supporting communicative development of infants and toddlers with hearing loss. Seminars in Speech and Language, 33(4), 273-279. 
Cho, T. H., Jun, S. A., \& Ladefoged, P. (2000). An acoustic and aerodynamic study of consonants in Cheju. Speech Sciences, 7(1), 109-141.

Cochlear. (2016, October 17). Ling 6 sound test. Retrieved from http:// hope.cochlearamericas.com/sites/all/themes/cochlear_hope/PDFs/SF_ Ling_6_SoundTest.pdf.

Cole, E. B. \& Flexer, C. (2015). Children with Hearing Loss: Developing Listening and Talking, Birth to Six. San Diego, CA: Plural Publishing.

Desjardin, J. L. (2003). Assessing parental perceptions of self-efficacy and involvement in families of young children with hearing loss. Volta Review, 103(4), 391-409.

Erber, N. (1982). Auditory Training. (pp. 92-94). Washington, DC: Alexander Graham Bell Association.

Glista, D., Scollie, S., Bagatto, M., Seewald, R., Parsa, V., \& Johnson, A. (2009). Evaluation of nonlinear frequency compression: Clinical outcomes. International Journal of Audiology, 48(9), 632-644.

Jeong, S. H. (2007). The study on phonetical information for speech recognition. The Research on Korean Language and Literature, 48, 135-160.

Johnson, K. (2011). Acoustic and Auditory Phonetics. Malden, MA: John Wiley \& Sons.

Kim, J. S. (2014). Paediatric audiology. In G. S. Kim, J. S. Kim, H. J. Kim, J. H. Bahng, K. W. Lee, J. H. Lee, et al. (Eds.) Introduction to Audiology (pp. 301-330). Seoul: Hakjisa.

Kim, J. S., Lee, K. D., \& Ji, Y. S. (2010). A study of the frequency analysis of the Korean meaningful monosyllabic words. Audiology, 6(1), 37-49.

Kim, J. S., Sin, E. Y., \& Jo, E. B. (2013). A study on initial · middle · final phoneme frequency analyses of the Korean meaningful monosyllabic words. Audiology, 9(2), 127-136.

Kim, G. S., Kim, J. S., Kim, H.J., Bahng, J. H., Lee, K. W., Lee, J. H., et al. (2013). A study on the formant comparison of Korean monophthongs according to age and gender-a survey on patients in oriental hospitals. Phonetics and Speech, 5(1), 73-80.

Ladefoged, P. (1993). A Course in Phonetics. (3rd ed.). Orlando, FL: Harcourt Brace.

Lee, J. H., Jang, H. S., \& Jeong H. J. (2005). A study on frequency characteristics of Korean phonemes. Audiology, 1(1), 59-66.

Lee, J. M. \& Bae, Y. N. (1987). Dictionary of Linguistics. Seoul: Parkyoungsa.

Lee, S. H., Park, M. H., \& Heo, M. J. (2003). Evaluation of response to speechKorean version, EARS-K. Daegu: Chungha Publications.

Ling, D. (1976). Speech and the Hearing-Impaired Child: Theory and Practice. Washington, DC: The AlexanderGraham Bell Association for the Deaf.

Ling, D. (1988). Foundations of Spoken Language for Hearing-Impaired Chil- dren. Washington, DC: The AlexanderGraham Bell Association for the Deaf.

Ling, D. (2002). The ling six-sound test. Paper presented at the 2002 Alexander Graham Bell Convention. St Louis, MO.

MED-EL. (2016, October 17). Ling 6 sound test. Retrieved from http://www. medel.com/blog/all-about-the-ling-six-sound-test/.

Ohala, J. J. \& Ohala, M. (1993). The phonetics of nasal phonology: Theorems and data. Nasals, Nasalization, and the Velum, 5, 225-249.

Pickett, J. (1980). The Sounds of Speech Communication. Baltimore, MA: University Park Press.

Scollie, S., Glista, D., Tenhaaf, J., Dunn, A., Malandrino, A., Keene, K., et al. (2012). Stimuli and normative data for detection of ling-6 sounds in hearing level. American Journal of Audiology, 21(2), 232-241.

Sennaroglu, L., Ziyal, I., Atas, A., Sennaroglu, G., Yucel, E., Sevinc, S., et al. (2009). Preliminary results of auditory brainstem implantation in prelingually deaf children with inner ear malformations including severe stenosis of the cochlear aperture and aplasia of the cochlear nerve. Otology and Neurotology, 30(6), 708-715.

Sin, J. Y. (2000). Understanding Speech Sounds: For the Base of Phonetics and Phonology. Seoul: Hankookmunhwasa.

Smiley, D. F., Martin, P. F., \& Lance, D. M. (2004, May 3). Using the ling 6-sound test every day. Audiology online. Retrieved from http://www. audiologyonline.com/articles/using-ling-6-sound-test-1087.

Song, Y. J., Lee, H. J., \& Jang, H. S. (2010). A Study on the Development of KNISEDASP for Auditory Training. Ansan: Korea National Institute for Special Education.

Tye-Murray, N. \& Clark, W. (1998). Foundations of Aural Rehabilitation: Children, Adults, and Their Family Members. San Diego, CA: Singular Publishing.

Winter, M. \& Kuk, F. (1998). Using a DSP instrument fitting protocol for pediatric cases. The Hearing Review, 5(10), 27-28.

Wolfe, J., John, A., Schafer, E., Nyffeler, M., Boretzki, M., \& Caraway, T. (2010). Evaluation of nonlinear frequency compression for school-age children with moderate to moderately severe hearing loss. Journal of the American Academy of Audiology, 21(10), 618-628.

Wolfe, J., John, A., Schafer, E., Nyffeler, M., Boretzki, M., Caraway, T., et al. (2011). Long-term effects of non-linear frequency compression for children with moderate hearing loss. International Journal of Audiology, 50(6), 396-404.

Yoshinaga-Itano, C. (2000). Assessment and intervention with preschool children who are deaf and hard-of-hearing. In J. G. Alpiner \& P. A. McCarthy (Eds.). Rehabilitative Audiology: Children and Adults (pp. 140177). Philadelphia, PA: Lippincott Williams and Wilkins. 